\title{
Protocolos de Montreal e Kyoto: pontos em comum e diferenças fundamentais
}

\author{
Montreal and Kyoto Protocols: common points and essential \\ differences
}

DARLY HENRIQUES DA SILVA*

Rev. Bras. Polít. Int. 52 (2): 155-172 [2009]

\section{Introdução}

O Protocolo de Montreal, criado em 1987, e o de Kyoto, de 1997, são tratados internacionais de grande porte. O primeiro, com 191 signatários, e o segundo, 174. Ambos dizem respeito à defesa do meio ambiente, evitando que atividades humanas (antrópicas) inviabilizem a vida sobre a Terra, poluindo-a e degradando-a. Mais recentemente, os Protocolos tratam de gases que provocam aquecimento global, embora diferentes, e de maneira distinta também.

Representam uma resposta internacional às conseqüências do modelo adotado de desenvolvimento industrial. Crescimento acelerado do setor produtivo e que, mesmo sob forma de ciclos de expansão ou desaceleração da atividade econômica, faz uso intensivo de matérias-primas fósseis para gerar energia e insumos para as plantas industriais.

O crescimento industrial, sobretudo após a II Guerra Mundial, trouxe consigo elementos indesejáveis que resultaram em poluição atmosférica e degradação ambiental, provocadas pelo uso de combustíveis fósseis e seus subprodutos gasosos. Como são os gases que dispõem de propriedades físico-químicas propícias à interação com a atmosfera, formada por gases também, é a matéria sob forma gasosa e combinada a que mais afeta a biosfera, que é o conjunto de todos os ecossistemas da Terra.

Ademais, salvar o planeta Terra de agentes nocivos tem sido uma bandeira dos movimentos ambientalistas, desde os anos 70, cujas atividades, às vezes exageradas, foram acolhidas, pela mídia e pela sociedade, como "uma boa causa a adotar e a seguir por todas as nações". Considerada atitude politicamente correta

\footnotetext{
* Analista de Ciência e Tecnologia do Conselho Nacional de Desenvolvimento Científico e Tecnológico $\mathrm{CNPq}$, Coordenadora Geral de Meteorologia, Climatologia e Hidrologia do Ministério da Ciência e Tecnologia - MCT, Doutora em Economia pela Universidade de Paris I Sorbonne (França), com estudos pós-doutorais em Política de C\&T e Espacial pela Universidade George Washington (darly@mct.gov.br).
} 
a se assumir na prática, a ideologia ambientalista moldou o pensamento em vários países, capitaneado pelos partidos políticos verdes.

Como as questôes negativas da utilização dos gases-alvo dos dois protocolos impactam fortemente a saúde pública e o meio ambiente, cabe aos governos resolvêlas. É o Estado o responsável por esses dois setores, portanto, pela elaboração de políticas públicas que os defendam contra os seus agressores. Como a atmosfera é universal e os problemas causados por esses gases não são restritos a territórios ou nações, a necessidade de acordos internacionais sob a égide das Naçôes Unidas tornou-se imperiosa. Assim, os Protocolos de Montreal e de Kyoto foram criados para promover o controle do uso de alguns gases nefastos à vida e ao meio ambiente.

Que as razóes científicas têm um denominador comum, pois controlam gases poluentes e a necessidade de proteger a vida contra os agentes nocivos, é consenso mundial, são as questôes político-econômicas que estão na origem das diferenças, com ênfase no setor energético. Questôes estas que resultam de política interna dos países industrializados, extrapoladas para a política externa e que ganham repercussão internacional. Este trabalho expõe algumas diferenças entre os dois protocolos, e tenta discuti-los à luz da literatura disponível. Inicia com a apresentação deles para que os pontos comuns sejam evidenciados, aponta as diferenças, enfatizando as componentes político-econômicas e pretende atualizar as informaçôes sobre as ações executadas no Brasil.

\section{Protocolo de Montreal}

O Protocolo de Montreal é um tratado internacional visando a substituir as substâncias que demonstraram reagir quimicamente com o ozônio na parte superior da estratosfera, as Substâncias Destruidoras da Camada de Ozônio (SDOs), como os grupos Clorofluocarbonos (CFCs), Halons, Tetracloretos de Carbono (CTCs) e Hidroclorofluorcarbono (HCFCs), emitidas em todo o globo, a partir dos processos de industrialização. Entrou em vigor em 1/1/1989 e sofreu emendas nas reuniōes de Londres (1990), Copenhague (1992), Viena (1995), Montreal (1997) e Pequim (1999).

O Fundo Multilateral (FML), criado em 1990, viabiliza o cumprimento do Protocolo. É administrado por um Comitê Executivo e suprido por países desenvolvidos. Os projetos apoiados pelo FML são executados em múltiplos países com a colaboração de agências internacionais das Nações Unidas: a dedicada ao Desenvolvimento, PNUD; ao Meio Ambiente, PNUMA; e à indústria, UNIDO, além do Banco Mundial.

\section{Problemas com a Camada de Ozônio}

A Camada de Ozônio é um "cinturão" de gases situado entre 10 e $50 \mathrm{~km}$ acima da superfície da Terra. No nível do solo, o ozônio é um poluente, mas na 
atmosfera superior, a estratosfera, protege as pessoas, animais e plantas, filtrando os prejudiciais raios ultravioletas (UV) do Sol. Nos anos 70, detectou-se o buraco na Camada de Ozônio sob a Antártica e em seguida no Pólo Norte.

Em 1985 o buraco na Camada de Ozônio foi considerado um problema ambiental para a comunidade internacional. Embora aparecesse sobre uma área relativamente desabitada, a sua descoberta foi crucial para a percepção pública sobre os problemas ambientais, porque, pela primeira vez, a ciência e as observações confirmaram o que eram especulações.

Segundo as pesquisas atuais, as substâncias que destroem a Camada de Ozônio são produzidas pelo homem e dividem-se nos seguintes produtos químicos: $\mathrm{CFC}$ 11, CFC-12, CFC-13, CFC-14, CFC-15; Halons, HCFCs e Brometo de Metila. Os CFCs são usados como propelentes na fabricação de aerossóis; em espumas; plásticos; ar condicionado, serviços de refrigeração, como agentes de processo e nos setores de solventes, e de uso em medicamentos (inaladores de dose medida).

Com a revolução patrocinada pelo avanço científico em Química e as possibilidades abertas para a sua aplicação por vários segmentos do setor produtivo, os gases CFC se tornaram insumos fundamentais para a indústria, desde a década de 30 do século XX, por serem baratos, quimicamente estáveis, não tóxicos, e com grande capacidade de absorver calor. No auge da era da sociedade de consumo do pós-guerra, sobretudo a americana, com o acesso de um contingente enorme de pessoas ao mercado de bens duráveis, e a expansão do uso de refrigeração, tanto doméstico quanto industrial, o emprego dos CFCs aumentou consideravelmente. Esses gases contribuíram para moldar o padrão sócio-econômico do pós-guerra, permitindo o enorme crescimento do mercado de consumo.

Se por um lado, a indústria se beneficiava com a utilização dos CFCs que permitia a expansão do mercado de consumo e do comércio de bens não duráveis, por outro lado, descobriu-se que os clorofluorcarbonos tinham um efeito colateral extremamente adverso aos seres vivos e agrediam o meio ambiente. Observou-se que se misturam à atmosfera, alguns atingindo a estratosfera, onde são dissolvidos em cloro livre pela radiação ultravioleta solar de alta energia. Por meio de interações complexas, esses átomos de cloro reagem com o ozônio, decompondo milhares de moléculas de ozônio para cada átomo de cloro.

A perspectiva do aumento de doenças sérias levou os políticos a criarem um acordo internacional para a substituição das SDOs. Inicialmente, para reduzir à metade o consumo dos CFCs em relação ao de 1986 e depois bani-los. A cooperação surtiu efeitos: a produção total de gases CFC de 1996 foi inferior a de 1960. A abundância combinada total de compostos que esgotam ozônio na atmosfera foi recorde em 1994, e a previsão era que a concentração do cloro e bromo consumidores de ozônio atingiria o pico na estratosfera antes de 2000, com a Camada de Ozônio lentamente se recuperando nos próximos 50 anos.

Entretanto, no Dia Internacional para a Preservação da Camada de Ozônio em 2008, a Organização Mundial de Meteorologia (OMM) advertiu que as 
mudanças observadas na estratosfera poderiam retardar a reconstituição dessa camada, apesar do reconhecimento que o Protocolo de Montreal proporcionou para a diminuição do desgaste. Em 16/9/2008, o buraco da Camada de Ozônio se espalhava por 27 milhões de $\mathrm{km}^{2}$ e foi de 25 milhões de $\mathrm{km}^{2}$ em 2007. A OMM afirmou, nesta ocasião, que os cientistas estão cada vez mais convencidos da relação entre a diminuição da camada de ozônio e a mudança climática e se expressou assim: "O aumento dos gases do efeito estufa na atmosfera contribuirá para um aumento das temperaturas na troposfera e na superfície do globo, enquanto será produzido um efeito de esfriamento na estratosfera, altitude na qual está a camada de ozônio."”

\section{Protocolo de Montreal no Brasil}

O Brasil aderiu à Convenção de Viena de 1985 para a Proteção da Camada de Ozônio, e do Protocolo de Montreal das Nações Unidas é signatário desde 1990. Conforme este Protocolo, países desenvolvidos que historicamente consumiram mais SDOs, financiam a erradicação dessas substâncias em países em desenvolvimento. O Brasil recebe aporte do FML desde 1993. O fundo não apóia pesquisa, apenas conversão industrial.

Como o consumo anual no Brasil das substâncias controladas listadas no Anexo-A do Protocolo foi inferior a $0,3 \mathrm{~kg}$ per capita, o País foi classificado como parte operacional sob o Parágrafo-1, Artigo 5 do Protocolo de Montreal, qualificado para uma programação especial de redução e para receber assistência técnico-financeira, inclusive envolvendo transferência de tecnologia.

A Secretaria Nacional de Vigilância Sanitária do Ministério da Saúde iniciou ações de controle, regulamentando (Portaria 01/10.08.1988) informações em rótulos de embalagens de aerossóis livres de CFCs. O Governo Federal criou o Grupo de Trabalho do Ozônio (GTO) via Portaria Interministerial 929 de 04.10.1991, facilitando a implementação do Protocolo. O Ministério da Saúde proibiu a produção e a venda de cosméticos, perfumes, produtos higiênicos e sanitários domésticos sob a forma de aerossóis contendo clorofluorcarbonos.

A Portaria no 4 de 11/1/1993 obrigou produtores, importadores, exportadores e usuários de substâncias sob Anexo A, B e C do Protocolo de Montreal a se registrarem no Ibama. O GTO elaborou o Programa Brasileiro para Eliminação da Produção e do Consumo das Substâncias que Destroem a Camada de Ozônio (PBCO) lançado em 7/1994 focado nas atividades de conversão industrial e análise de todos os segmentos produtores e usuários. A partir da experiência do

\footnotetext{
1 EFE-Genebra (2008). Buraco da camada de ozônio sobre Antártica já é maior que em 2007, diz OMM [http://g1.globo.com/Noticias/Tecnologia/0,,MUL761590-6174,00-BURACO+DA+CAMADA+DE+O $\mathrm{ZONIO}+\mathrm{SOBRE}+\mathrm{ANTARTIDA}+\mathrm{JA}+\mathrm{E}+\mathrm{MAIOR}+\mathrm{DO}+\mathrm{QUE}+\mathrm{EM}+\mathrm{DIZ}+\mathrm{OMM} . h$ tml] disponibilidade: $16 / 09 / 2008$.
} 
PBCO, aprovou-se a Resolução13/1995 do Conselho Nacional do Meio Ambiente (Conama) que concentrou as prioridades da participação do Brasil sobre a conversão tecnológica industrial para a eliminação dos CFCs. Neste mesmo ano, o Governo Federal instituiu o PROZON, o Comitê Executivo Interministerial para a Proteção da Camada do Ozônio, tendo como coordenador, o Ministério do Meio Ambiente. ${ }^{2}$

As açōes do Governo correspondem ao estabelecimento de quota de redução via altas taxas federais e estaduais para todos os produtores locais, com limitaçōes graduais e banimentos sobre a importação das SDOs. Até 1995, o Brasil era um dos principais consumidores de gases que prejudicam a Camada de Ozônio. Até 2005, mais de 200 projetos foram aprovados no Brasil pelo Protocolo de Montreal, a fundo perdido, resultando na eliminação de $95,4 \%$ do consumo de CFC no País, conforme relatório 2007 do MMA.

O Plano Nacional de Eliminação dos Clorofluorcarbonos de 2002 destinouse à eliminação do uso dos CFCs em todos os setores até 1/1/2010. Possibilitou o treinamento de técnicos "refrigeristas"; o combate ao comércio ilegal de gases destruidores da Camada de Ozônio via treinamento de oficiais de alfândega e de técnicos do IBAMA e a eliminação do uso dessas substâncias no setor farmacêutico. ${ }^{3}$ Ademais, ações específicas conjuntas do Ministério da Agricultura, Pecuária e Abastecimento com a Agência de Vigilância Sanitária e o Ibama concentram-se na eliminação do Brometo de Metila até 1/1/2015.

Baseado na Lei 10.165/2000, na Resolução do Conama 267/2000 e na Instrução Normativa Ibama 37/2004, o governo Brasileiro regula e controla toda a produção, comercialização e consumo de substâncias controladas pelo Protocolo de Montreal. O Brasil assumiu compromisso com a Secretaria do FML de consumir 420 toneladas de CFC em 2008 e apenas 74 toneladas em 2009.

A produção e o consumo de HCFCs será congelada nos níveis de 2013, a partir de 2016, com eliminação em 2040. O Brasil realizou em 2008 um diagnóstico do setor de HCFCs com indicação de consultores e colaboração da indústria nacional ${ }^{4}$. Foi lançada também Consulta Pública à Proposta de Instrução Normativa do IBAMA que regulamenta a restrição de importação do HCFCs. ${ }^{5} \mathrm{O}$ Tetracloreto de Carbono (CTC), empregado no processo de produção do cloreto de polivinila (PVC), tem uso controlado pelo Protocolo de Montreal como agente de processo e não como matéria-prima. O Brasil deixou de produzir CTC em 2004.

Em novembro de 2008 foi realizada uma reunião do Comitê Executivo do Protocolo e das Partes do Protocolo de Montreal em Doha que tratou da eliminação

\footnotetext{
2 Ministério do Meio Ambiente (sem data), Plano Nacional de Eliminação de CFCs, Relatório 2007, p.9. 3 Ministério do Meio Ambiente, sem data, O que o Brasil está fazendo para a proteção da Camada de Ozônio? Plano Nacional de Eliminação de CFCs, p.10.

4 Ministério do Meio Ambiente, PROZON, Ata 9/11/2007.

5 Ministério do Meio Ambiente/IBAMA, Portaria No15 de 16/04/2008.
} 
das SDOS; o cumprimento das metas; além da definição de recursos financeiros do FML para os projetos piloto e foram aprovados US \$ 490 milhōes para o triênio 2008-2011 para o FML financiar projetos de países fora do Artigo 5.

\section{Protocolo de Kyoto}

Acordo internacional que fixa metas para limitar a poluição pela queima de combustíveis fósseis causadoras do efeito estufa. Durante a Conferência Rio92 da ONU sobre Meio Ambiente, mais de 200 países adotaram a Convenção-Quadro das Nações Unidas sobre Mudanças Climáticas, que entrou em vigor em 1994. Conferências anuais das Partes se seguiram, culminando com a assinatura do Protocolo de Kyoto em 1997.

O Protocolo prevê uma redução total das emissões de 5,2\% entre 2008 e 2012 em comparação aos níveis de 1990. Apenas 42 países industrializados do Anexo I do Protocolo ${ }^{6}$ estão sujeitos a essas metas que variam de um signatário para outro. Os países da União Européia têm que cortar as emissóes em $8 \%$, enquanto o Japão se comprometeu com 5\%. Países em desenvolvimento não tiveram de se comprometer com metas específicas. Como signatários, no entanto, precisam manter a ONU informada sobre seu nível de emissōes, bem como devem buscar o desenvolvimento de estratégias para tratar as mudanças climáticas.

Os Estados Unidos não ratificaram o Protocolo, ao contrário da Rússia que permitiu que a cláusula de adesão ${ }^{7}$ fosse satisfeita para o tratado poder entrar em vigor em 16/2/2005. Ratificado por 36 países do grupo dos mais ricos, o Protocolo de Kyoto limita emissões dos seis gases que provocam o efeito estufa: o metano $\left(\mathrm{CH}_{4}\right)$; o óxido nitroso $\left(\mathrm{N}_{2} \mathrm{O}\right)$; o hidrofluorcarbono (HFC); o perfluorcarbono (PFC); o hexafluorsulfúrico $\left(\mathrm{SF}_{6}\right)$ e o gás carbônico $\left(\mathrm{CO}_{2}\right)$.

Além da redução interna, os países têm mais três alternativas: investir em projetos de redução em outras nações do Anexo I; comprar créditos de carbono em bolsas mundiais que comercializam esse produto; ou alocar recursos em projetos de mitigação de poluentes em países em desenvolvimento, no âmbito do Mecanismo de Desenvolvimento Limpo, o MDL. ${ }^{8}$

Os países também podem ganhar créditos por atividades que aumentem a sua capacidade de absorver carbono, como o plantio de árvores e a conservação do solo. $\mathrm{O}$ Acordo de Marrakech, que regulamentou o MDL, criou um potencial de mobilização de recursos para projetos de redução de emissóes de GEE ou reflorestamento.

6 O Anexo I contém os países membros da Organização de Cooperação para o Desenvolvimento Econômico (OCDE) e os países do antigo bloco soviético.

7 Estipula no mínimo 55 países do Anexo I que compatibilizem juntos pelo menos 55\% do total da quantidade de dióxido de carbono equivalente emitida por eles em 1990. Ver Convenção-Quadro sobre Mudança do Clima e o Protocolo de Kyoto publicado pela Comissão de Meio Ambiente e Desenvolvimento Sustentável , Câmara dos Deputados, Ed(2005), Brasília:Plenarium, 84p, Apresentação e p.43.

8 Cada crédito de carbono representa uma tonelada de gás carbônico equivalente não lançado na atmosfera. 
Como os países da OCDE são os que necessitam diminuir suas emissóes, são eles os compradores em potencial de créditos de carbono, enquanto que os países em transição econômica podem ser anfitriôes de projetos de implementação conjunta, como a Ucrânia, Rússia e Romênia.

O total que o mercado de emissões pode gerar até 2012 é de US \$ 50 bilhões. Até 12/2007, 49 países tiveram 860 projetos MDL em andamento, enquanto 2000 aguardavam análise. O MDL evitou a emissão de 100 milhões de toneladas de $\mathrm{CO}_{2}$. Todavia, um estudo realizado pelo grupo internacional que examina as metodologias empregadas para gerar créditos de carbono, após análise por amostragem de 100 desses 860 projetos, apontou que até 50\% dos projetos em curso podem ter sido "maquiados" para aprovação.?

Blüchel afirma:

“(...) quem pensa continuar a impregnar a Terra com $\mathrm{CO}_{2}$ até o fim, a ele é oferecido uma solução elegante por esses guardiōes verdes da virtude - ele pode comprar créditos. Como funciona este comércio moderno de indulgências? Muito simples: compra-se certificados de emissão de dióxido de carbono. Os preços para este comércio de pecados são diferentes: para grandes pecados paga-se um pouco mais, para pequenos um pouco menos. O dinheiro gasto na indulgência, por exemplo, por um fabricante de automóveis ou um fornecedor de energia, é adicionado na fatura, de modo que nestes negócios duvidosos ninguém fica sem lucro." ${ }^{10}$

Dentre os compromissos do Brasil junto à Convenção-Quadro das Nações Unidas sobre Mudança do Clima está o de desenvolver e atualizar, periodicamente, o Inventário Nacional de Emissões e Remoções Antrópicas de Gases de Efeito Estufa, cobrindo os setores de energia; processos industriais; uso de solventes; agropecuária; mudança no uso da terra e florestas; e tratamento de resíduos. Este inventário contabiliza as emissões antrópicas por fontes e remoções por sumidouros dos gases de efeito estufa não controlados pelo Protocolo de Montreal, além de fornecer uma descrição geral das providências para implementar a Convenção. O documento contendo tais informações é chamado de Comunicação Nacional ${ }^{11}$. Em 2006, o setor de transportes, em especial o rodoviário, foi o que mais contribuiu para as emissões no Brasil (42\%); seguido pela indústria (30\%); a geração de eletricidade e o setor energético (15\%) e o agropecuário com apenas 4,5. ${ }^{12}$

9 Folha de São Paulo, Mecanismo de Kyoto é ineficaz contra $\mathrm{CO}_{2}$, 19/12/2007, Ciência, p.A24,

10Blüchel, Kurt G, Ed.(2008) A Fraude do efeito estufa, aquecimento global, mudança climática: os fatos, São Paulo: Publishing House, 317p, p. 70-71,

11 O Brasil tem uma meta de redução da taxa de desmatamento de $70 \%$ até 2018, segundo o Ministro Carlos Minc que apresentou na reunião de Poznan da ONU em 12/2008 o Plano Nacional de Mudanças Climáticas (Folha de São Paulo, Ban elogia Brasil, que alivia para desmatador, 12/12/2008, Ciência, p.A16),

12 Alvim, Carlos F.; Eidelman, Frida; Mafra, Olga; Ferreira, Omar C.(2008) Avaliação das Emissões Evitadas pela Política Energética Brasileira no Setor Transporte Rodoviário. Revista Economia e Energia, No 70, outubro-novembro 2008, ano XII, p.32-33, 
O $1^{\circ}$ inventário brasileiro de emissão dos gases do efeito estufa foi divulgado em 2004 com dados de 1990-94. O 2º, concluído em 12/2008, cobre de 1995 a 2000, portanto, com 8 anos de defasagem entre os dados e sua publicação. Estes documentos apontam que a área de maior complexidade corresponde ao uso da terra e florestas, com $75 \%$ das emissões brasileiras registradas na primeira contagem do inventário. Nesses inventários não se incluiu as atividades da marinha mercante, por exemplo, de interesse do comércio internacional e cujos estudos revelam grandes emissões de $\mathrm{CO}_{2}{ }^{13}$, tampouco a emissão das capitais com $50 \%$ da população brasileira. Sem o conhecimento dos gases poluentes que chegam à atmosfera e para onde vão, como e com quais se combinam, não se terá informações precisas sobre as emissões globais de GEE. ${ }^{14}$

A propósito, a Secretaria de Meio Ambiente e a Companhia de Tecnologia de Saneamento Ambiental do Estado de São Paulo decidiram concluir até 2010 o inventário das emissões paulistas de GEE para subsidiar o estabelecimento de metas globais ou setoriais pelo Estado. O setor energético definiu em $20 \%$ a redução das suas emissões de $\mathrm{CO}_{2}$ para 2020. Desta forma, entendem contribuir com o novo regime internacional no Pós-Kyoto, que exigirá metas dos países emergentes. ${ }^{15}$

\section{Líderes no comércio de créditos de carbono}

Brasil, China e Índia apresentam o maior número de iniciativas de MDL registradas no organismo da ONU que coordena essas atividades. Apesar de ter sido pioneiro em aprovar um projeto MDL, o Brasil vem perdendo posiçóes no ranking internacional do mercado de carbono. Por possuir uma matriz energética limpa ${ }^{16}$, baseada em hidroeletricidade, que não emite quantidade importante de $\mathrm{CO}_{2}$, o Brasil fica em desvantagem em relação a outros países de grande dimensão e economias crescentes, e que utilizam nas suas matrizes energéticas fontes de origem fóssil.

Projetos de geração de energia limpa para as nações com matrizes energéticas baseadas em combustíveis fósseis são os que apresentam os melhores resultado para ajudar no cumprimento das metas estabelecidas no Protocolo de Kyoto. ${ }^{17} \mathrm{~A}$ Índia assumiu a liderança, ficando o Brasil na $4^{a}$ posição em número de projetos com reduçôes certificadas de emissões. Os dados são do Banco Mundial, e divulgados

13 Folha de São Paulo, Marinha mercante emite 4,5 do $\mathrm{CO}_{2}$ mundial, 14/02/2008, p.A20.

14 O Globo, Mapa de riquezas do solo ajuda a combater aquecimento global, Ciência, 05/03/2009, p. 32.

15 Folha de São Paulo, Mudanças Climáticas e São Paulo, Tendências/Debates, 17/02/2009, p.A3

16 Esta situação pode mudar pois o Governo brasileiro pretende dobrar o número de usinas poluentes (Folha de São Paulo, 7/1/2009, Ciência, p. A12).Termelétrica para Carajás emitirá 2,2 milhōes de toneladas/ano de $\mathrm{CO}_{2}$ com a Vale licenciando usina a carvão na Amazônia (Folha de São Paulo 12/11/2008, Ciência, p.A12).

17 Souza, Fabíola S. (2007) Mecanismos de Desenvolvimento Limpo e Créditos de Carbono: As Potencialidades do Brasil. Monografia para obtenção do Master in Business Administration, Fundação Instituto de Administração/USP, São Paulo, abril/2007, mimeo 73 p. 
em 26/3/2007 pelo especialista em Meio Ambiente do BIRD, Werner Kornexl, no seminário internacional "Mercado de reduções de emissões" promovido pela Comissão de Valores Imobiliários. O Brasil tem 94 projetos registrados e 118 aprovados na Convenção-quadro das Nações Unidas para Mudanças Climáticas, enquanto que a Índia tem 187 registrados.

Além disso, o mercado movimentou US\$ 3 bilhões em 2006. Os projetos brasileiros de MDL giram em torno de 100 mil toneladas por ano, considerado pouco pelo BIRD, e por isso, menos atrativo para os compradores. Ao Banco interessa projetos de 500 mil toneladas ao ano. O potencial deste mercado é de 1,5 bilhôes de toneladas, pouco menos da metade dos projetos de MDL aprovados até então, completa Kornexl.

A ONU avaliou que os países industrializados estão fora da meta de redução. Apenas 4 países da União Européia têm chance de cumpri-las, e prevê o pior para 2010: aumento de $10 \%$ em relação a 1990, com queda total de emissões de $\mathrm{CO}_{2}$ de 3\% entre 1990 e 2000, mas devido ao declínio econômico das ex-repúblicas soviéticas e mascarando aumento de $8 \%$ nas emissões entre os países ricos.

Responsável pela emissão de mais de $25 \%$ do $\mathrm{CO}_{2}$, os EUA se retiraram das negociações sobre o Protocolo de Kyoto em 2001, alegando que a sua implementação prejudicaria a economia americana. Um dos argumentos é que não há exigência sobre os países em desenvolvimento para reduzirem as suas emissões ${ }^{18}$. O Presidente Bush comentou concordar com as reduçôes por meio de medidas voluntárias e novas tecnologias no campo energético.

Entre as grandes economias em desenvolvimento, China e Índia também ratificaram o protocolo, mas como países em desenvolvimento, com todos os direitos a que fazem jus no âmbito desse Protocolo, o que deixou o governo americano insatisfeito, sobretudo em relação àqueles que têm no carvão mineral, a sua principal fonte de energia para movimentar economias em expansão, como a China, esta agora a $3^{\text {a }}$ economia do mundo, atrás dos EUA e do Japão.

A Austrália aderiu ao Protocolo de Kyoto em 3/12/2007, o que expôs mais ainda a posição desfavorável de Washington perante o mundo. Segundo a delegação americana presente à Conferência do Clima em Bali em 12/2007, os EUA não prejudicarão as negociações sobre o acordo para substituir o tratado que expira em 2012. ${ }^{19}$

\section{Divulgação dos Protocolos de Montreal e de Kyoto}

Se nos anos 80, o buraco da Camada de Ozônio ganhou repercussão internacional como ameaça aos seres vivos, a partir da década de 90 foi o aquecimento global, causado pelos gases do efeito estufa e as mudanças climáticas

18 Não há exigência sobre nenhum país, mas compromisso dos seus governantes perante a ONU.

19 Folha de São Paulo, Austrália ratifica Kyoto e isola os EUA, Ciência 4/12/2007, p. A18. 
que ganharam a página principal dos noticiários mundiais com ameaças à vida. Graças a isso, a sociedade tem muito conhecimento sobre o Protocolo de Kyoto quase nenhum sobre o de Montreal.

Por iniciativa dos Governos dos EUA e Grã-Bretanha, foi criado em 1988, o Painel Intergovernamental sobre Mudanças Climáticas (IPCC), subordinado ao Programa Ambiental da ONU (PNUMA) e à Organização Meteorológica Mundial (OMM), também da ONU. O Painel tem por missão avaliar informaçōes científicas, técnicas e sócio-econômicas visando a entender riscos induzidos pelas mudanças climáticas, seus potenciais impactos e opções para mitigação e adaptação. O IV Relatório do IPCC de 02/2007, culpando o homem como responsável pelas mudanças climáticas globais, impactou fortemente sobre a comunidade internacional, os formadores de opinião e os tomadores de decisão nos Governos. ${ }^{20}$

Devido a um verão seco e com altas temperaturas nos Estados Unidos em 1988, cientistas reagiram sobre os riscos de um aquecimento global. Políticos se somaram a este grupo, culminando com o Premio Nobel da Paz dado a Al Gore e ao IPCC em 2007. Em 1989, 700 cientistas assinaram uma petição apresentando o aquecimento climático como ameaça à humanidade, e apelaram aos governos para reduzir a emissão de $\mathrm{CO}_{2}$. Além de alguns climatologistas, os signatários eram na maioria politólogos, juristas, economistas, filósofos. Uma composição semelhante está preservada até hoje no Painel do Clima da ONU composta por 2500 membros. Blüchel continua:

“...os anos seguintes pareciam indicar que a suspeita do aquecimento da Terra poderia ser justifica: a partir dos anos 80 do século XX, ...Este desenvolvimento climático encaixou-se otimamente no conceito dos profetas de catástrofes e logo foi avaliado como precursor dos cenários de horror do $\mathrm{CO}_{2}$ prognosticados. Quase ninguém procurou por outras causas, e quando o fez, o público levado em uma determinada direção, praticamente não deu atenção."21

Ainda segundo Blüchel, o movimento que culminou na criação do IPCC teve a iniciativa do lobby da indústria nuclear. A petição já continha o apelo para revisão do futuro desse tipo de energia pois usinas nucleares praticamente não liberam $\mathrm{CO}_{2}$. Assim, após a desativação de muitas usinas nucleares na Europa, principalmente na Alemanha, estas passaram a ser uma alternativa verde no mundo inteiro, tornando-se elegíveis para substituição da fonte fóssil.

Para entender o papel do IPCC, é importante saber que as mudanças climáticas têm duas naturezas distintas e nem todas causam aquecimento climático.

20 Nobre, Carlos Afonso (2007) Mudanças Climáticas Globais e o Brasil: porque devemos nos preocupar, Boletim da Sociedade Brasileira de Meteorologia, Vol.31, No 4, abril de 2007, p.7-11.

21 Blüchel, Kurt G. (2008), op. cit Ref.10, p.167-169. 
Uma relacionada à variabilidade natural do clima, responsável pelas diversas eras glaciais, antes mesmo da presença do homem na Terra. Desastres naturais causaram grandes catástrofes, como a erupção de vulcão na Indonésia há 75 mil anos, com emissão de quantidades enormes de $\mathrm{CO}_{2}$ na atmosfera e cuja cinza vulcânica, quando reagiu com água, eliminou muitos seres humanos por envenenamento. Ademais, o efeito estufa natural permite a vida sobre a Terra conservando uma temperatura média adequada. A outra forma de mudanças climáticas é produzida pelas atividades do homem no uso da terra ou em atividades industriais, portanto, antrópicas. Os desastres naturais que presenciamos resultam da ação combinada dessas duas modalidades. Qual a origem delas e como agem em conjunto? A ciência ainda não tem respostas.

O IPCC analisa os trabalhos científicos que têm origem apenas nas atividades antrópicas. Pesquisadores com formação variada estudam o efeito estufa e abastecem o IPCC com informação. Isto faz com que os trabalhos do Painel sejam incompletos para mostrar a realidade das mudanças climáticas globais. Além disso, mais de 90\% dos artigos aceitos pelo IPCC, que não é uma sociedade científica, mas tem caráter intergovernamental, e por isso segue orientação política de governos, são de autores de países desenvolvidos, mesmo quando trata de assunto do hemisfério sul, com uma parcela insignificante dos países em desenvolvimento. ${ }^{22}$

A literatura sobre o protocolo de Kyoto, aquecimento global e as mudanças climáticas tem se calcado, sobretudo, nos relatórios do IPCC que contam com a credibilidade de 80 a $90 \%$ da comunidade internacional, sendo que o restante compõe o grupo dos "céticos" que considera o efeito estufa uma fraude.

$\mathrm{Na}$ Dinamarca, a posição dos líderes políticos e dos analistas se contrapõe fortemente quando o assunto é aquecimento global. A Ministra de Clima e Energia Connie Hedegaard, visitando o Brasil em 2008, afirmou que a posição do seu governo é confiar nas estimativas do IPCC. Em 2050 já será tarde demais para combater o aquecimento climático, e que tem que agir agora senão o aquecimento global vai se acelerar de tal maneira que será muito caro revertê-lo, e a humanidade não conseguirá manter o padrão atual de vida. ${ }^{23}$

De outro lado, existem compatriotas da Ministra, como Lomborg ${ }^{24}$ que considera exagerada a preocupação com o aquecimento climático global. Empregando dados estatísticos e interpretando a história da evolução do clima desde quando há registros, este autor contesta o que considera uma visão apocalíptica, ladainha ambientalista, difundida durante anos por ecologistas radicais, com interesses outros que os da preservação da vida e do meio ambiente.

22 Dos quase 30 mil trabalhos analisados pelo IPCC para subsidiar o IV Relatório do Painel, 5 foram feitos na América Latina (Folha de São Paulo,Brasil não monitora mudanças do clima, 11/04/2007, p.A12).

23 Revista VEJA, Entrevista Connie Hedegaard, A guerreira do clima, 8/10/2008, p.17, 20-21.

24 Lomborg, Böjrn Ed(2002) O ambientalista cético-revelando a real situação do mundo, São Paulo: Campus, $541 \mathrm{p}$. 
A posição de um líder governamental com decisões a tomar pelas quais será julgado pela história é mais difícil que a dos analistas, que mesmo empregando metodologia científica, têm menor responsabilidade do que autoridades. Além disso, um líder de um país industrializado tem compromissos em preservar o alto padrão de vida dos países ricos, seus pares, e tema para discussão na próxima conferência do clima na Dinamarca sobre o Pós-Kyoto. Porém, sem dados suficientes e confiáveis sobre as mudanças climáticas que exigem pelo menos 30 anos de observação ininterrupta, segundo a OMM, produzem-se mapas e atlas mundiais desses fenômenos com o intuito de orientar interessados em questôes ambientais, professores e responsáveis por políticas públicas, inclusive sobre o Brasil ${ }^{25}$. Qual o valor desse tipo de informação?

\section{Soluções para agora, problemas para amanhã?}

Há duas décadas, as empresas de petróleo introduzem $\mathrm{CO}_{2}$ em alguns dos seus poços para retirar o resto de combustível do subsolo. Tal prática é empregada como uma das formas de seqüestro de carbono. Como o $\mathrm{CO}_{2}$ resultante da combustão desse mesmo petróleo tornou-se o maior inimigo do meio ambiente, esse procedimento passou a ter uma nova função, a de "eliminar" $\mathrm{CO}_{2}$. Segundo o IPCC, será necessário seqüestrar 25 bilhôes de toneladas de $\mathrm{CO}_{2}$ por ano até 2050, e o enterro do carbono pode colaborar para o cumprimento desta meta, ajudando a eliminar pelo menos $21 \%$. Para atingir esse objetivo, o plano dessas empresas cobre várias fases. $\mathrm{O}$ carbono emitido pelas refinarias é capturado por uma chaminé e o gás é introduzido e aprisionado no subsolo. O Brasil, sozinho, tem capacidade para armazenar o equivalente ao que o planeta emite em 80 anos, afirma João Marcelo Ketzer, coordenador do Centro de Excelência em Pesquisa sobre Armazenamento de Carbono da PUC/RS. As áreas para extração de carvão mineral ou os aqüíferos salinos também podem servir como locais de estoque. Segundo especialistas do Centro de Pesquisa da Petrobrás, CENPES, há expectativa de que até 2014, estoque-se $\mathrm{CO}_{2}$ da ordem de dez milhões de toneladas ao ano. Caso esta meta seja atingida, este projeto será um dos maiores de seqüestro geológico: um trilhão de toneladas em reservatórios de petróleo, dez trilhões em aqüíferos e 40 bilhões em minas de carvão. ${ }^{26}$

A logística da captura em uma refinaria ou em uma usina é complexa e inclui riscos de segurança. $\mathrm{O} \mathrm{CO}_{2}$ pode vazar no transporte, ou no próprio reservatório causando problema ambiental. O custo da tecnologia é alto, com o transporte exigindo a construção de dutos, como o de gás natural. No Brasil, as injeções em larga escala de carbono são em terra na Bahia e sob o mar na bacia de Campos.

25 Dow, Kirstin; Downing, Thomas E. Ed (2007), O Atlas da Mudança Climática-O mapeamento completo do maior desafio do planeta, UK:Earthscan, 120 p.

26 Folha de São Paulo, Brasil quer virar líder em enterro de gás carbônico Ciência, 20/01/2008, p.A51. 
Os experimentos pioneiros em grande escala de enterro de carbono foram na Noruega, sob o mar, pela petrolífera local Atatoil; no Canadá, em terra, com o carbono capturado nos EUA armazenado pela canadense EnCana; e na Argélia, com gás natural. Cada um seqüestra até dois milhões de toneladas de $\mathrm{CO}_{2}$ por ano. ${ }^{27}$

Segundo Blüchel ${ }^{28}$, embora o $\mathrm{CO}_{2}$ não seja inflamável nem tóxico, é mais pesado que o ar, podendo, por isso, asfixiar tudo o que tem vida. Em 1986, uma erupção súbita de $\mathrm{CO}_{2}$ em um lago vulcânico em Camarões aniquilou animais e 1.500 pessoas. E questiona: quem tem o direito de levar o "lixo de gás" e para aonde. O armazenamento está sujeito à que lei? Ao código de mineração, como o gás natural? Quem é o responsável pelos depósitos subterrâneos?

Além das bombas químicas e biológicas que tanto aterrorizam nações, inclusive os EUA, existe possibilidade que se crie armas tectônicas, cujos potenciais de força de destruição em massa são desconhecidos. Isto já pode estar ocorrendo e mantido sob sigilo pelas empresas, Estados e não-Estados (terroristas). Pesquisas científicas mostraram, a partir de 1945, que o homem poderia agir sobre as imensas forças de tensão da crosta terrestre. Por isso, testes nucleares foram regularizados e proibidos em ambientes subterrâneos.

O exército dos EUA se livrou de seu rejeito tóxico em Fort Dedrick empregado em guerra química e biológica com a coleta dos gases nervosos em barris e depois afundados no mar. Outras substâncias tóxicas foram bombeadas para um poço de 4.000 metros de profundidade, perfurado para esta finalidade, perto do Arsenal Rocky Mountain no Colorado. Durante o período no qual o procedimento foi adotado, registrou-se 710 abalos sísmicos, 18 de magnitude média, enquanto que, nos 80 anos anteriores ocorreram somente três abalos sísmicos nessa região Existe uma possibilidade concreta de o $\mathrm{CO}_{2}$ provocar terremotos criados pelo homem. Bolhas de dióxido de carbono resultam de tais bombeamentos nas entranhas da Terra produzindo explosões devastadoras. Na Polônia, Alemanha e embaixo do Mar do Norte, entre Escócia Noruega, instalou-se os primeiros super cemitérios para o $\mathrm{CO}_{2}$. De acordo com uma estatística da Agência Internacional de Energia da ONU, o homem produz atualmente cerca de 26 bilhóes de toneladas de dióxido de carbono. Estas quantidades enormes de gases deveriam ser bombeadas para o centro da Terra? (Blüchel, 2008, p.137).

Na mesma linha de argumentação, se o IPCC declarou o homem culpado pelas mudanças climáticas causadas pelo mau uso do solo (IV Relatório 02/2007), o que diria então sobre o uso inadequado do subsolo e das profundezas desconhecidas dos oceanos, este, o maior responsável pelo clima, e cujas conseqüências não são discutidas?

Recentemente moradores de São Paulo sentiram um tremor de terra por volta das 21 h de 22/4/2008 cujo epicentro ocorreu a 215 km de São Vicente, no mar e

27 Folha de São Paulo, op. cit. Ref. 26, 20/01/2008.

28 Blüchel,Kurt.G. (2008), op. cit. Ref. 10, p. 138. 
atingiu $5,2^{\circ}$ na escala Richter, com o tremor a cerca de $10 \mathrm{~km}$ de profundidade ${ }^{29}$. Com tantas atividades subterrâneas com relação à extração de petróleo no mar, e as poderosas ondas de choque causadas por movimentação da crosta terrestre, o Observatório Nacional firmou convênio com o CENPES/Petrobrás para financiar a instalação de uma rede sismográfica para monitorar os terremotos no Brasil, com o projeto aprovado pela Agência Nacional de Petróleo. Os recursos financeiros são provenientes da lei que rege a exploração dos grandes campos de petróleo e correspondem a $1 \%$ dos royalties para pesquisa e desenvolvimento.

\section{Comentários finais}

Os Protocolos de Montreal e Kyoto resultaram de preocupações mundiais com o meio ambiente, sua alteração pelo homem e as conseqüências adversas que essas mudanças podem produzir sobre a vida na Terra.

Por meio de cálculos, o MMA mostra que é possível estabilizar as emissões dos gases HCFCs em 2011 evitando 14 milhōes de toneladas irem para a atmosfera entre 2011 e 2040. Como os HCFCs têm um potencial muito maior de absorver calor e esquentar a Terra que o $\mathrm{CO}_{2}$, mesmo uma pequena economia de suas emissóes teria um impacto expressivo no clima. A proposta significaria evitar a emissão de 5,5 bilhôes de toneladas equivalentes de gás carbônico, ou seja, a meta completa do Protocolo de Kyoto. ${ }^{30}$

Flannery ${ }^{31}$ afirma que, dentre os tratados internacionais em andamento, o Protocolo de Kyoto talvez seja o mais duramente criticado, o que lhe parece estranho devido aos seus modestos objetivos, e que são apenas dois, econômicos e políticos. Enquanto que o Protocolo de Montreal conta com o Fundo Multilateral e apóia projetos-piloto supervisionados por um Comitê Executivo, o de Kyoto não tem um fundo próprio e depende do MDL, cuja avaliação não tem sido a mais favorável.

O tratado Pós- Kyoto deverá estar pronto até dezembro de 2009, data limite para a assinatura de um novo tratado. A próxima Conferência sobre Mudanças Climáticas, em Copenhague, discutirá como enfrentar o aquecimento global ${ }^{32}$. A maioria dos cientistas que estuda o clima diz que as metas instituídas em Kyoto são insuficientes. O acordo visa reduzir as emissóes nos países industrializados em 5\%, enquanto é praticamente consenso entre os cientistas que defendem o corte nas emissões que

29 Folha on line (2008). São Paulo é atingida por tremor de 5,2 graus na escala Richter [http://wwwl.folha. uol.com.br/folha/cotidiano/ult95u394686.shtml]: disponibilidade: 22/04/2008.

30 Gabeira, Fernando (2007). Combate a gás de camada de ozônio poupa "um Kyoto". [http://gabeira. locaweb.com.br/noticias/noticia.asp?id=3851] disponibilidade: 30/05/2007.

31 Flannery, Tim, Ed(2007) Os Senhores do Clima. Rio de Janeiro-São Paulo: Record, 364 p, em especial o Capítulo 24, A Estrada para Kyoto.

32 Revista VEJA (2008), op.cit. Ref.23, p 20-21. 
seria preciso uma redução de $60 \%$. Portanto uma diferença tão grande faz com que os $5 \%$ não sejam, de fato, uma meta realista. Diante disso, os termos finais de Kyoto receberam críticas que o protocolo terá pouco impacto no clima e é inútil sem a participação americana.

Outros, no entanto, dizem que, apesar das falhas, o protocolo é importante porque estabelece linhas gerais para futuras negociações sobre o clima. Consideram que ele ajudou vários países transformarem em lei metas de reduções das emissões.

Por outro lado, o caso do esgotamento da camada de ozônio e a solução mediante protocolos restritivos, como o de Montreal, são vistos como um exemplo de sucesso, em que a comunidade mundial se uniu e priorizou o meio ambiente em detrimento das ambiçôes econômicas. Por esse motivo, o caso do ozônio costuma ser citado como uma aplicação vitoriosa do princípio da cautela e da consciência ambiental em geral.

Para o Ministério do Meio Ambiente brasileiro, o cumprimento de metas do Protocolo de Montreal já colaborou mais para a proteção climática do que o Protocolo de Kyoto. Entre 1990 e 2000, a redução global nas emissóes de gases que prejudicam a Camada de Ozônio alcançou 25 bilhôes de toneladas de $\mathrm{CO}_{2}$ equivalentes, volume quase 5 vezes superior aos 4,5 bilhóes de toneladas de $\mathrm{CO}_{2}$ que devem ser eliminadas nas emissões dos países em desenvolvimento entre 2008 e 2012. No Brasil, entre 2000 e 2007, evitou-se a emissão de 36,5 mil toneladas de CFCs, correspondentes a cerca de 360 milhóes de $\mathrm{CO}_{2}$ equivalentes.

A mudança de processos industriais foi fundamental para que os objetivos de redução anual das SDOs fossem alcançados. CFCs foram substituídos, como Hidroclorofluorcarbonos (HCFCs) e Hidrofluorcarbonos (HFCs). No entanto, os CFCs remanescentes (como em geladeiras muito antigas) e essas substâncias alternativas ameaçam o clima. Conforme o Protocolo de Montreal, países desenvolvidos devem reduzir o uso de HCFCs em 75\% até 2010 e em 99,5\% até 2020. Mas a produção global desses gases tem aumentado nos países em desenvolvimento, sendo $70 \%$ do total na China.

Reestruturação industrial e adaptação tecnológica exigem custos altos e tempo. Os processos que utilizam gases químicos e inovações tecnológicas precisam de tempo de maturação para ser viáveis em escala industrial. Entretanto, apesar dessas dificuldades, conseguir o cumprimento da proibição do CFC foi rentável. Saiu relativamente barato encontrar substitutos aos CFCs, ao mesmo tempo em que as vantagens foram bem nítidas. Um relatório para o Environment Canada, o órgão de proteção canadense de meio ambiente, estimou que o custo global total até 2060 da implementação dos protocolos de CFC seria de uns 235 bilhões de dólares de 1997.33

A maior parte da produção dos gases controlados pelo Protocolo de Montreal é feita nos países industrializados ou por multinacionais com plantas nos países em

33 Lomborg, Björn (2002), op.cit.Ref.24, p.329-331. 
desenvolvimento, por isso, o controle é mais fácil, e a maioria deles é insumo para outros produtos. Os gases controlados pelo Protocolo de Kyoto, especialmente o $\mathrm{CO}_{2}$, são resultantes da queima de produtos usados em vários setores econômicos e também de utilização do solo, como desmatamento e queimadas de grandes áreas que se misturam a outros gases na atmosfera e são muito mais difíceis de controlar. Além disso, existe a influência de outros ambientes (oceanos, hidrosfera, Antártica) que interagem com a atmosfera gerando o clima.

Marcelo Leite, jornalista e colunista da Folha de São Paulo, resume a obra do jornalista Oliver Tickel "Kyoto 2, como administrar a estufa global" como "desconstrução de Kyoto"34. "Tickell fornece uma medida convincente da inoperância de Kyoto comparando-o com o Protocolo de Montreal. Adotado uma década antes para combater outro problema da atmosfera, o buraco na camada de ozônio estratosférico, Montreal acabou contribuindo quatro vezes mais do que Kyoto para mitigar o aquecimento global, pois alguns dos gases que atacam o ozônio são também gases do efeito estufa." Para Tickell, o protocolo não funcionou por colocar metas por países e pretender que governos nacionais beneficiem-se e fiscalizem, concomitantemente, os mecanismos de mercado estabelecidos para reduzir as emissões de gases do efeito estufa. A crítica é focada nos créditos de carbono, a alma de Kyoto, segundo esse autor, que acrescenta que o mercado de carbono mais festejado, o "esquema europeu de comércio de emissões" serviu para desviar bilhôes de euros dos consumidores para empresas de energia.

Por ser um grande emissor de $\mathrm{CO}_{2}$, pesa muito a rejeição dos EUA em não ratificarem o Protocolo de Kyoto, embora tenham adotado o de Montreal. Essa questão tem um elemento chave sem o qual qualquer discussão sobre aquecimento global ou mudanças climáticas antrópicas é inócua. Trata-se da energia e da matriz energética de qualquer país. A produção de energia é diretamente proporcional à atividade industrial de um país, e por isso, influi decisivamente no cálculo do seu PIB, que reflete a riqueza de uma nação. Por sua vez, o aumento do PIB depende de uma matriz energética robusta, e se possível diversificada e independente do provimento de matéria-prima internacional. Portanto, é estratégico para cada nação fazer uso máximo do potencial energético próprio. Esta foi a lição deixada pelos choques de petróleo dos anos 70. Dependência energética pode frear o crescimento econômico mesmo de naçóes desenvolvidas.

Por outro lado, por que usar energias renováveis, se ainda existe muito combustível fóssil para ser extraído durante os próximos séculos, mesmo jazidas ainda não descobertas, como estudos já revelaram, somado ao fato que vários países têm sua economia fortemente dependente da exploração e comercialização desses produtos, como o petróleo? Em 2008, o preço do barril do petróleo chegou a US\$147 e as economias não colapsaram por isso. A crise de 2008 não

34 Leite, Marcelo (2008) [http://ecourbana.wordpress.com/2008/10/19/em-busca-do-kyoto-perdido]/ disponibilidade:19/10/2008. 
é de escassez de energia como nos anos 70. "A crise é a hora de taxar o petróleo e salvar o clima".35

Pesquisadores viajando em 2008 a bordo de um navio russo dizem ter provas de que milhões de toneladas de metano, gás do efeito estufa 20 vezes mais potente que o $\mathrm{CO}_{2}$ vai para a atmosfera a partir das profundezas do Oceano Ártico. Depósitos de $\mathrm{CH}_{4}$ aprisionados nas profundezas emergem como grandes bolhas, coincidindo com o aquecimento da região e o desaparecimento das capas de gelo que cobriam as águas da região, segundo o jornal britânico The Independent. Esse depósitos são importantes pois no passado houve liberação similar provocando uma elevação rápida das temperaturas, mudanças climáticas abruptas e extinções em massa, diz o jornal.

O pesquisador Örjan Gustafsson (Universidade de Estocolmo) descobriu o primeiro campo em que a liberação do $\mathrm{CH}_{4}$ era tão forte que o gás não tinha tempo de dissolver-se na água do mar, emergindo em grandes bolhas ${ }^{36}$. Todavia, se o metano é a grande preocupação desses cientistas, mas está relacionado na Terra com atividades biológicas e erupções vulcânicas, embora seja um gás também controlado pelo Protocolo de Kyoto, o grande vilão do clima é o $\mathrm{CO}_{2}$. Por que o tratamento dado pelo Protocolo e pela mídia é tão diferenciado quando se trata do impacto desses dois gases? Porque o $\mathrm{CO}_{2}$ é o subproduto do uso do combustível fóssil mais empregado nas atividades humanas nos países desenvolvidos.

O apelo antrópico por parte dos ambientalistas visa a mudanças de modos de produção e implica em pressões internacionais, pois mexe com interesses nacionais e conflitantes. Essas mudanças no padrão de produção baseiam-se na necessária alteração das fontes poluidoras de energia dos países. No caso do $\mathrm{CO}_{2}$, não se trata de substituição de um gás por outro, mas como eliminar o resíduo da queima de combustível fóssil. Por outro lado, usando também argumentos antrópicos, há os que lutam por energias renováveis como modelo de energia limpa, e como alternativa viável em grande escala para o século XXI, posição defendida por países em desenvolvimento com grande potencial para produzir e comercializar biocombustíveis.

Nesta disputa político-econômica acirrada, o papel do $\mathrm{CO}_{2}$ é bem mais importante nas negociações internacionais que o do $\mathrm{CH}_{4}$, ou qualquer outro gás controlado por acordo internacional. $\mathrm{O} \mathrm{CH}_{4}$ pode ser empregado como fonte de energia, mas sem valor de mercado, como o carvão ou o petróleo, este protegido por organizações como a OPEP para garantir que permaneça no século XXI, o padrão energético do século XX.

35 Folha de São Paulo, Entrevista James Hansen, Ciência, 15/03/2009, p.A24. Hansen foi fundamental para a criação do IPCC em 1988.

36 Gustafsson, Örjan [http://www.estadao.com.br/vidae/not_vid246814,0.htm] disponibilidade: $24 / 09 / 2008$. 
Ameaças sobre os recursos naturais, não sustentabilidade, e tecnologias tornaram-se comuns. Nem todas se concretizam. A do Clube de Roma e seu relatório "Limites do Crescimento", concluído em 1972 para a ONU, apontou os riscos do crescimento exponencial da população mundial versus uma expansão linear de alimentos e de recursos naturais, prevendo o caos. A ameaça climática é mais complexa, mas foi quantificada no Relatório Stern sobre a Economia das Mudanças Climáticas (10/2006). O exemplo mais notável de ameaças globais foi a do "BUG do Milênio" que mobilizou toda a comunidade internacional para o maior desastre da sociedade pós-moderna. Pânico no sistema financeiro e bancário totalmente informatizado; bolsas quebrando; a população desnorteada e os governos fariam planos de emergência para mitigar a catástrofe.

As pesquisas devem avançar mais para fornecer conhecimento e dados para prevenção, mitigação e adaptação às mudanças climáticas. Somente estudos com dados e informações completas e o tempo comprovarão se o aquecimento global é real ou mais um "Bug" do milênio.

Recebido em 24 de março de 2009 Aprovado em 10 de julho de 2009

\section{Resumo}

Os Protocolos de Montreal e Kyoto, tratados internacionais de defesa do meio ambiente e da vida, controlam gases que provocam o buraco na camada de ozônio e o efeito estufa, respectivamente, resultantes de atividades industriais e uso da terra. O artigo enfatiza pontos comuns e diferenças entre eles, fornecendo atualização dos protocolos.

\section{Abstract}

Montreal and Kyoto Protocols, international treaties, aim at safeguarding the environment and life by controlling the use of gases which deplete the ozone layer and cause the greenhouse effect, respectively, due to industrial and land use activities. The article highlights common points and differences and provides an update discussion about the protocols.

Palavras-chave: Protocolos de Montreal e Kyoto.

Keywords: Kyoto and Montreal Protocols. 